\title{
Tapping the Potential of Pigai Automated Writing Evaluation (AWE) Program to Give Feedback on EFL Writing
}

\author{
Geng Jingxin*, Abu Bakar Razali \\ Faculty of Educational Studies, Universiti Putra Malaysia (UPM), Serdang, 43400, Selangor, Malaysia
}

Received October 26, 2020; Revised December 7, 2020; Accepted December 18, 2020

\section{Cite This Paper in the following Citation Styles}

(a): [1] Geng Jingxin, Abu Bakar Razali, "Tapping the Potential of Pigai Automated Writing Evaluation (AWE) Program to Give Feedback on EFL Writing," Universal Journal of Educational Research, Vol. 8, No. 12B, pp. 8334-8343, 2020. DOI: 10.13189/ujer.2020.082638.

(b): Geng Jingxin, Abu Bakar Razali (2020). Tapping the Potential of Pigai Automated Writing Evaluation (AWE) Program to Give Feedback on EFL Writing. Universal Journal of Educational Research, 8(12B), 8334-8343. DOI: 10.13189/ujer.2020.082638.

Copyright $\bigcirc 2020$ by authors, all rights reserved. Authors agree that this article remains permanently open access under the terms of the Creative Commons Attribution License 4.0 International License

\begin{abstract}
With the rapid development of educational technology, studies on automated writing evaluation (AWE) program have been gaining more ground in EFL writing education, particularly due to its potential in giving continuous, formative feedback on students' writing performance. However, little research has paid attention to the effectiveness of giving and receiving AWE feedback on improving EFL learners' writing performance from cognitive, constructive and sociocultural dimensions. By drawing on the Cognitive Constructivism theory, particularly the Cognitive process writing theory, and Sociocultural theory in particular the notion of the Zone of Proximal Development (ZPD) and Scaffolding, this article reviews past studies done on the use of AWE programs in teaching English writing and this article also attempts to propose for an AWE program called Pigai to be embedded as a teaching paradigm for EFL teachers to apply in writing classes for Chinese EFL students in China in giving continuous and formative feedback to their students, in order to improve English writing teaching and positively affect EFL students' writing performance. At the end of the article, the authors also offer strategies of the implementation of the Pigai AWE program through a framework for Pigai to be used with EFL learners.
\end{abstract}

Keywords Automated Evaluation Program (AWE), English as a Foreign Language (EFL), Pigai Program, EFL Writing, Writing Performance

\section{Introduction}

Feedback is widely regarded as a crucial factor in English writing teaching [22]. Due to research on teacher feedback and peer feedback attracting scholars' concerns, the rapid development of technology in the past decade has made automated writing evaluation (AWE) feedback gain more ground in the field of teaching English as a foreign language (EFL). Although many previous studies have tended to examine AWE's accuracy and validity, as well as its users' perceptions of a number of AWE programs according to their developer's different designs of assessing purposes and functions, very little research had been conducted on the effectiveness of AWE feedback on improving learners' overall writing performance [22, 37]. In short, there is still a paucity of empirical research on the effectiveness of AWE feedback integrated by writing pedagogy.

Based on the review of a selected body of literature, the purpose of this article is to discuss the potential of a specific AWE program, called Pigai, in providing feedback to instruct Chinese EFL students writing performance from the perspectives of a Sociocultural lens informed by the zone of proximal (ZPD) and scaffolding theory, and Cognitive Constructivism theory, specifically 
the Cognitive process theory of writing which may shed new light on AWE feedback in EFL writing instruction. Specifically, in this paper, the authors also argue for the needs of Cognitive process theory of writing (which also mediates students' learning by feedback on multiple-drafts; [25]) to integrate with the AWE feedback instruction; and the notions of ZPD and scaffolding in the use of AWE feedback in English as a foreign language (EFL) writing teaching. In this regard, the authors share ideas, suggestions, and implications for the implementation of AWE feedback in the field of writing teaching particularly in the EFL context.

In writing this article, the authors engaged in a review of carefully selected research articles. In total, the authors systematically and carefully selected 26 articles for the review. There are 24 selected articles that were published in Q-indexed journals from 2010 to 2019, such as Language Testing, Assessing writing, Journal of Second Language Writing, CALICO Journal, Language Assessment Quarterly, British Journal of Educational Technology, Innovations in Education and Teaching International, System, ELT Journal, Journal of Educational Computing Research, JALT CALL Journal, English Teaching and Learning, Computer Assisted Language Learning, Educational technology research and development, Journal of Physics: Conference Series, IEEE Engineering Management Review, and Educational Psychology. Due to the relatively limited resources on the Pigai AWE program, two related research articles that were published in Critical CALL-Proceedings of the 2015 EUROCALL Conference and International Journal of Smart Technology and Learning were included. Among these research, 15 were conducted using mixed research methods, 7 research adopted a quantitative method, 3 research used a qualitative method, and 1 review article. Moreover, there are only 4 research adopted experimental research as part of the research. In terms of research sites, 7 research were conducted in the mainland of China. The rest of the research were all done in other parts of the world, such as Hong Kong, Taiwan, Australia, and America.

In the article, the authors mainly discussed the grounds for the AWE program, AWE program for EFL Learners, Pigai AWE program for EFL students, theoretical underpinnings for the implementation of the Pigai AWE program, and the framework for using the Pigai AWE program in the EFL writing lesson. Then, the authors present the conclusion at the end of the article.

\section{The Grounds for Automated Writing Evaluation (AWE) Program}

The field of education has always been greatly influenced by the rapid development of technology. Rooted in automated essay scoring (AES) system and computer-mediated feedback technology, Automated Writing Evaluation (AWE) programs are initially designed for writers in English-domain countries [45], and have also now been implemented extensively in the field of English education as well as teaching of English as a foreign language (EFL) writing instruction in the last decade [30]. As a product of artificial intelligence, the AWE program is identified by providing real-time synchronous scores, both holistic scores [33] and analytic scores, and more importantly automated individualized diagnostic feedback on users' written pieces [5] in different aspects of writing traits respectively.

Being an assessment tool, the reliability of the AWE programs' consistency, accuracy, and validity is an essential factor for writing instruction. Many literature show that the automated scores provided by the AWE program are highly consistent with the scores given by human raters [9, 30]. For instance, Cotos [9] contends the consistency agreement between the AWE tool called Intelligent Academic Discourse Evaluator (IADE) and human raters at a high level. Regarding the validity of the automated feedback, in their study, Chapelle, Cotos, and Lee [30] compared the use of Criterion and IADE, in which both of these programs are AWE programs. The findings indicate that both of these two AWE programs consistently provide more positive feedback than the negative ones, however, with different types of diagnostic feedback. For example, IADE does not focus on writing errors but provides complementary writing instruction on how to write research articles; while Criterion provides diagnostic feedback in terms of writing traits, including organization, mechanics style, grammar, and language use.

In examining the validity and reliability of the AWE system, research has shown strong evidence on the potential use of the AWE program being an assessment tool in standardized writing tests. In Rudner, Garcia, and Welch's study [36], the IntelliMetric AWE system performs very consistently by providing similar agreement feedback as found from statistic features for approximately 500 the Graduate Management Admission Test (GMAT) essays, which is superior to 2 human raters. Also, the agreement between human raters and the IntelliMetric system averaged a high correlation $(\mathrm{r}=.83)$. Similarly, Ramineni [34] conducts quantitative research based on the standardized college admission test context. Findings from the study revealed that the automated scoring system for the customized scoring model of the AWE-Criterion program is very much in line with human scores.

That said, a number of research have also provided evidence of the issues with the consistency of AWE programs. For instance, in Cotos' [9] research, even though he found positive evidence on the consistency of the IADE AWE program with human raters, the findings also show negative evidence about the feedback that 
comes from the IADE AWE program, such as miscommunication of the intended functional meaning. In another instance, in a longitudinal mixed-methods study where Li et al., [27] investigated the correlation between the scores from an AWE tool (called Criterion) and human rating scores on 4 papers of learners, including holistic score and analytic score. They found the scoring consistency between e-rater and human raters to be unstable, ranging from low to a moderate level, which means AWE scores cannot inform students' overall writing competence consistently with the human raters' scoring. The accuracy and validity of AWE diagnostic feedback play a great effect on how the instructor uses it appropriately. Even though the instant holistic score and the analytic score could reduce the teacher's heavy scoring burden to the individual learner, given all the evidence above, treating the AWE score as an independent summative assessment tool for students' overall writing competence would be problematic.

As can be seen from the discussion above, there have been quite a number of academic studies conducted on the potentials of the AWE program in writing instruction from different practical aspects, including investigating the accuracy and validity of the AWE program in providing scoring and corrective feedback, the users' perceptions on the role of the AWE program in writing instruction, and its effectiveness on improving learners' writing ability. While these studies mostly yielded positive results on the use of the AWE program in teaching and learning writing, as can be seen from the review of past studies above, there are also some issues with using the AWE program, particularly with the consistency of the scoring by AWE and human raters, which means that the AWE program is not ideal to be used solely as the reference by the students without getting feedback from other people, such as their teachers. In this regard, the authors also argue that the students should not also use AWE but also to receive feedback from their teachers and ideally from their peers as well.

\section{Automated Writing Evaluation (AWE) Program for EFL Learners}

Previous research also has been done for the potentials of the AWE program in EFL writing instruction or in improving EFL learners' writing performance. For instance, Li et al., [27] examined the perceptions of both the EFL teacher and students towards the AWE program provided automated general scores. Based on the interview data, the results indicated both the EFL teacher and students show a low level of trustworthiness on high scores, but they treated low scores as an indicator for low writing performance. In their study, Tang and Rich [39] asserted the Writing Roadmap (WRM) AWE is effective to motivate students to revise their written drafts over and over again by interacting with the WRM system continuously in the Chinese context, which is an important factor in the improvement of their writing competence. On top of that, they also suggested for the WRM program to serve as a teaching facilitator, as it was able to provide dynamic assessment and automated feedback continuously, which enhances writing instruction effectively.

In examining the effectiveness of the AWE program on improving learners' writing ability, Wang, Shang, and Briody [44] contend that the use of the CorrectEnglish AWE program enhanced students' writing performance in the aspect of linguistic accuracy in Taiwan. In a similar vein, Liao [28] conducted time-series research to examine the effectiveness of using the Criterion AWE program with the process-based writing approach on reducing undergraduates' grammar errors in writing in Taiwan. The result unveils four main types of grammar errors that students used to make before the use of Criterion (i.e., fragments, subject-verb disagreement, run-on sentences, and ill-formed verbs); and all of these grammar errors were treatable after the prompts from Criterion automated feedback, but the effect varies in terms of the type of grammar errors.

In a follow-up study, Liao [29] further investigated how to enhance the grammatical accuracy of EFL learners' writing by using Criterion AWE while the EFL students were being assisted by the process-based writing approach teaching method. The result indicated that the continuous revision process according to the feedback from Criterion made the students use the language gap noticing and metacognitive strategies repeatedly, which improved the learners' writing accuracy. It is worth noting that the feedback from the AWE program, as well as its working system, makes the learning process gradual, incremental, and recursive. Furthermore, the use of the AWE program breaks the students' passive learning mode from the traditional teacher-centered assessment process, to not being linear any more [39]. More importantly, the instant AWE feedback also motivated learners, to some extent, to revise continuously their written works which enhances their longer-term shifts in developing writing skills.

On the other hand, some previous researches have also found some drawbacks of the AWE feedback for EFL learners. For example, in Hoang and Kunnan's study [21], MY Access! AWE tool was found not to be a useful independent instructional tool, because of its limited scoring ability, as well as the low detective ability on off-topic essays and plagiarism. Some researchers also observed that some AWE tools may perform effectively only on local errors [28, 29] but ineffectively at diagnosing global language concerns, such as content, idea development [1]. A few other research also reveals concerns on the interaction between learners and AWE software which lack human communication [42, 29]. In this regard, these current AWE systems are not adequate 
enough to be an independent instruction tool in the EFL writing process [24, 44], but must be instead used by the teacher while also having the teachers as the people overseeing and giving their feedback to the students as well.

\section{Pigai Automated Writing Evaluation (AWE) Program for EFL Students}

There are quite a number of different brands of AWE programs and they vary according to the developers' design. At present, Criterion and MYAccess! are known to be the two preferable choices of the instructors in English as the first language (L1) and English as a second language (ESL) context. However, due to the monolingual feedback (which is designed only in English), it does not provide much help to EFL learners, particularly to novice writers, such as those in China, where many of these EFL learners might not have a good understanding of the automated feedback done in English [12]. Moreover, the mistake that Chinese EFL learners often make is the negative transfer from their mother tongue (i.e., Mandarin) when writing in English where their written English language errors are usually out of the error detective range for these AWE programs that are developed in Western countries. In this regard, an AWE system called Pigai (which literally means 'correction' in Chinese Mandarin) program has been developed by a Chinese AWE developer and has become quite popularly used for EFL teachers and learners in China since 2011.

The Pigai AWE program was designed by Beijing Word Network Technology Co. Ltd., based on the application of Corpus Linguistic of a large scale of human-scored essay, Artificial Intelligence, and Cloud technology. By making a comparison between learners' essays and the corpus through lexicon, sentence, organization, and content these four aspects, and after a certain algorithm, Pigai shows the scores, including holistic scores and analytic scores (in terms of grammar, organization, mechanics, content, and vocabulary) and personalized diagnostic feedback in the microstructural level (e.g., vocabulary, language use, mechanics) and macro-structural level (e.g., content and organization) to the learners almost immediately after the submission of their writing piece. According to Wang's [43] interpretation of Pigai Intelligent Online English Writing Correction System from www.pigai.org, Pigai aims at solving problems, regarding the negative transfer of Chinglish (i.e., Chinese English), grammar errors, the imbalance of linguistic competency from the side of learners, and the lowering the burden by the teachers in having to correct these mistakes manually by themselves. Particularly, Pigai's automated feedback is provided in the Chinese language, which benefits Chinese EFL learners in understanding the feedback clearly and effectively.
According to estimation by service provider Pigai.org, it is the most extensively implemented commercial AWE program in China at present. As illustrated by Zhang and Zhang [50], "The Pigai system has already assessed more than 400 million essays submitted by over 20 million students from as many as 6,000 schools in China” (p. 29).

The notion of AWE feedback as a pedagogically attractive writing instruction tool lies in its ability to provide continuous and constructive feedback to EFL writers as well as opportunities to review and revise their work until they are satisfied with it. In doing so, learners revise their drafts by referring to the formative automated feedback [37]. More importantly, the automated feedback that the Pigai program provides is indirect and heuristic, such as giving a prompt on language use, and indicating and reminding of errors on collocation. In addition, the Pigai program also supports the technology to conduct online teacher feedback, as well as online peer feedback on students' writing products. From the perspective of pedagogical practices, the online teacher feedback mode which can be done via Pigai offers an effective way for the instructor to monitor students' writing process than traditional face-to-face instruction [13, 46], and on the other hand, it also promotes student-centered learning [29] and develops students' learner autonomy [49,39]. Through the online Pigai AWE program, EFL students have multiple chances to engage in their writing practices and their writing quality is supervised by the integration feedback of automated feedback, online teacher feedback, and online peer feedback. In addition, it also helps students to overcome the dilemma caused by nervousness and shyness, which usually happens in EFL students from Asian countries [46, 24] when they interact with their teacher and peers in the traditional face-to-face classroom [8].

With the prevalence of the Pigai program in China, a number of studies have been conducted to investigate its use in the EFL English writing class. In a survey conducted by $\mathrm{Lu}, \mathrm{Li}$, and $\mathrm{Li}$ [31], evidence shows the use of the Pigai program improves Chinese college EFL learners' writing skills as well as increased their learner autonomy. Similar evidence is also uncovered in Jiang's investigation [23] where she found that there is a positive relationship between the number of times of the revision that students made and the scores that the students received. Also, in terms of analyzing e-portfolios formed in the Pigai program, in Chen and Xia's study [7], the result shows that Pigai automated feedback helps students improve their writing quality, particularly in the aspects of accuracy and organization. Zhang and Zhang [50] listed Pigai's four merits that enable Chinese EFL student users to engage in its use are: Intelligence, Inclusiveness, Interactiveness, and Immediacy. Specifically, intelligence and inclusiveness stand for the merits of its scoring system and AWE diagnostic feedback. This is due to the holistic score that the Pigai program provides in aspects of 
vocabulary, sentence, structure and organization, and content, based on a large corpus of standard English. Pigai was also found to have offered more types of diagnostic feedback than other AWE programs, including feedback in linguistic accuracy (particularly in detecting Chinglish), positive reinforcement for users' good expression, and extended learning on collocation. Pigai also promoted the notions of Interactiveness and Immediacy where these two distinctive features were capitalized due to the technology supporting integrating online teacher feedback and online peer feedback functions through Pigai's platform, and the speed of the feedback was generated -1.2 seconds (as cited from the introduction of the Pigai Program on the website http://www.pigai.org/).

On the other hand, there are also some studies that have found some limitations of the Pigai AWE program on EFL learners. For instance, Bai and $\mathrm{Hu}$ [2] explored Pigai's accuracy in giving feedback and Chinese undergraduate students' perceptions of the Pigai program. Results indicate that the precision of Pigai's automated feedback is $45.77 \%$. Compared with the accuracy of the Criterion program (57.5\%) as reported by Dikli and Bleyle [11], Pigai's accuracy is rather low. Researchers also found students' response to Pigai's feedback is rather inconclusive leading to the quality of revision varies according to the level of user's language proficiency. However, it is important to note that the majority of students in this study still perceived positively Pigai’s real-time feedback. Similarly, Yan [47] conducted an investigation to explore Pigai's accuracy and students' perceptions on the use of the Pigai. The results are in line with Bai and Hu's research [2], where they also found the inadequacies of accuracy, as well as functions that do not involve thought-provoking, logical judgment, and the corpus of poetic expressions may affect the effectiveness of the Pigai program on improving EFL learner's writing competence.

In this view, there is an essential need to study whether the use of the Pigai program is effective or not on EFL Chinese learners' writing performance. Since the findings of past studies have been quite contradictory and insufficient, it is necessary to find out from an empirical research such as experimental study and by using different variables, such as the embedded use of teacher feedback and AWE feedback, peer feedback and AWE feedback, and AWE feedback.

\section{Theoretical Underpinnings for the Implementation of Pigai AWE Program}

The innovations of the Pigai AWE program can be utilized under the theoretical framework of Cognitive Constructivism theory (particularly the Cognitive process writing theory) and Sociocultural theory (particularly the notions of the Zone of Proximal Development (ZPD) and Scaffolding).

Constructivism is a theory that views "learning as an interpretive, recursive, building process by active learners interacting with the physical and social world" [17] (p. 30). Meanwhile, cognitivists, such as Graves [19] address the writing learning process as not linear, but recursive. Graves also stresses the significance of arousing the writer's awareness of being an audience as well as peer feedback. Based on the notions of cognitive constructivism, there are three important factors highlighted in the writing learning process: 1) the learner, 2) the role of the instructor, and 3) the learning environment. In the Pigai AWE program, it can be argued that the students experience active learning through the active engagement of themselves with the instructors through a conducive and supportive learning platform that is Pigai. Through the Pigai program, they start to write when they receive the assignment given by the teacher through the program, and they would work on this one assignment with multiple drafts. After the submission of each draft, they receive the real-time automated diagnostic feedback in terms of grammar, vocabulary, organization, content, and mechanics, as well as holistic comments by Pigai itself and also by the teacher if the teacher chooses to do so. In order to submit the assignment with better quality, they improve their writing drafts in terms of sufficient automated feedback with multiple practice opportunities. Thus, students construct their writing knowledge actively when they write through the Pigai program.

Meanwhile, the Sociocultural theory developed by Vygotsky [41] presents the process of language learners' cognitive development through social acts. This theory argues that the understanding of children's cognition and learning is social and cultural other than individual phenomena. The core concepts of Sociocultural theory include the Zone of Proximal Development (ZPD), mediation, regulation, scaffolding, internalization, private speech, activity theory, and genetic method, which have been applied in the field of education, particularly in EFL teaching and learning. As addressed by Gilles and Pierce [18], "language cannot be separated from learning, because it is both essential to learning and enhanced by learning. Neither can language and learning be separated from interaction with others.” (p. 61)

The concept of ZPD which is rooted in Sociocultural theory [41] mainly deals with space or zone between the individual's actual development level and the potential development level. Once a zone has been achieved with the help of a more knowledgeable "mediator", a new zone with an upper level presents for the learner. In this case, the Pigai program is the "mediator". When students engage in writing through this AWE program, they will receive real-time diagnostic automated feedback in terms of grammar, vocabulary, organization, content, and 
mechanic based on the individual's actual development level. After getting instructions or feedback from the "mediator" on their written work, the revised written piece will reach the potential development level. Then, students come to their individual's new zone with the upper level, where another round of revision starts and instructed recursively. Thus, their writing performance improves through the interaction with the Pigai program (automated feedback received from the program). Also, the teacher's constructive feedback through the Pigai program is another form of "mediator". Students will receive teacher online formative feedback after the submission of each draft, which leads students to reach their potential development level. Based on the teacher's online feedback, students' new zone with upper level constantly will be achieved and replaces the old one by the recursive revision process. In addition, online peer feedback through Pigai is also a type of "mediator". The feedback from advanced level peers enhances the potential development level of the less proficient learners. After the revision according to received peer feedback, finally, students' performance will come to the optimum potential development level.

Another crucial concept based on Sociocultural theory [41] is Scaffolding. Bruner [4] defines scaffolding as "the steps taken to reduce the degrees of freedom in carrying out some tasks so that the child can concentrate on the difficult skill she is in the process of acquiring” (p19). Maybin, Mercer, and Stierer [32] describe the traits of scaffolding as the "temporary, but essential, nature of the mentor's assistance” (p.186). The main approach to providing scaffolded support through the use of the Pigai program involves the diagnostic feature of its automated feedback. During the writing process, learners will receive help from a more knowledgeable assistant to deal with the difficulties they meet in their writing. In this situation, the Pigai program serves as the more knowledgeable assistant, providing diagnostic and formative feedback in the aspects of grammar, vocabulary, content, organization, and mechanics, which helps students detect their errors and guide them to improve successfully. When they reach upper-level ZPD, the original scaffolding will be replaced by the new set of diagnostic feedback based on the revised writing piece.

Graves [19] states that writing is not a linear but a recursive process, and he also stressed the importance to raise the awareness of the writer being an audience by peer review activity. Rooted in this concept, a group of composition practitioners began to investigate the writing process from cognitive psychology and psycholinguistics perspectives [3, 10, 15, 48, 35]. By using think-aloud composing protocols to investigate learners' composing processes, Flower [14] and Flower and Hayes [15] extended their research findings to develop the theory into establishing a cognitive process writing theory model [15] which focused on writer's mental development and problem-solving during the writing process. This well-established cognitive model consists of three main components: the task environment, long-term memory, and composing (see Figure 1).

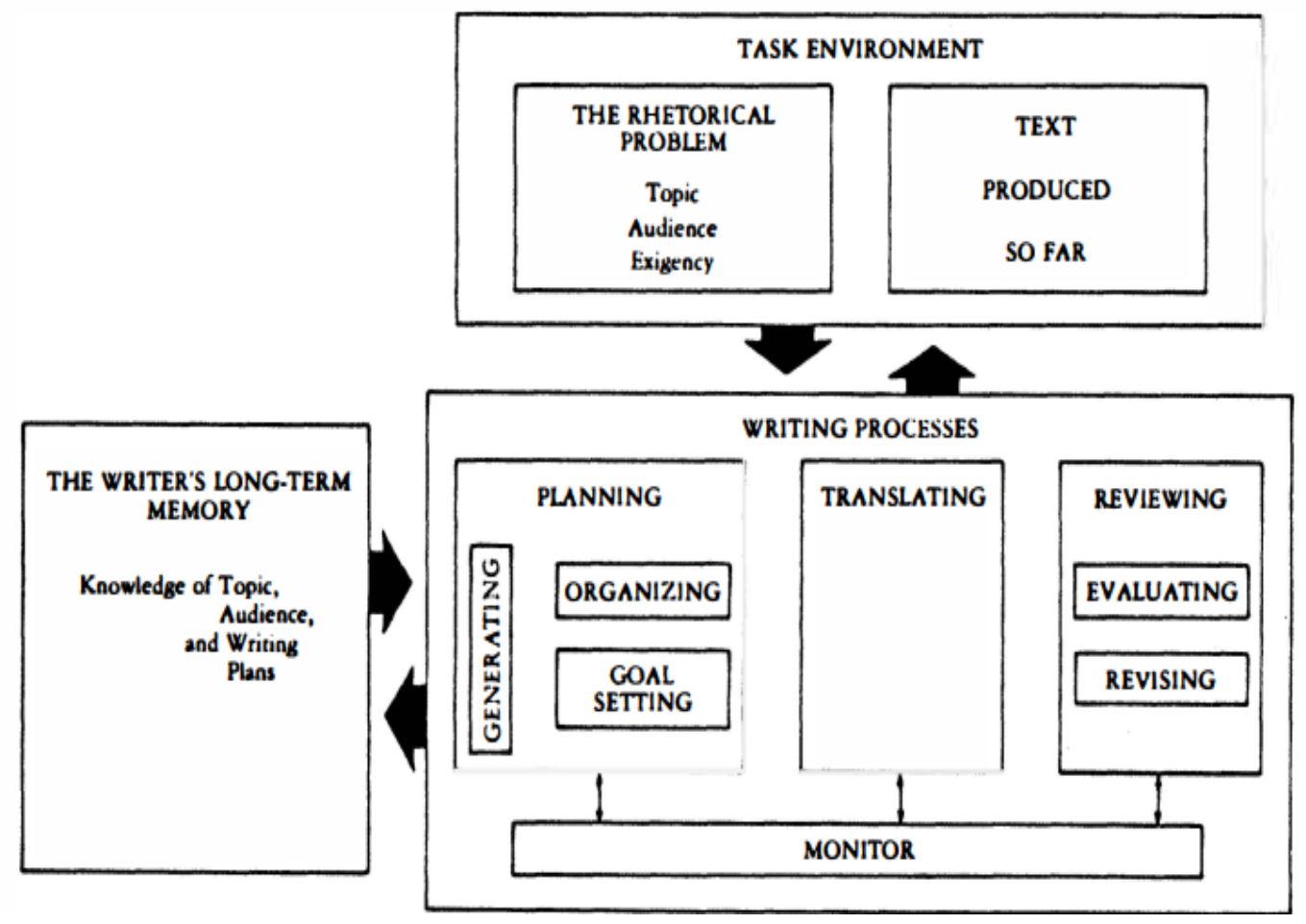

Figure 1. A Model of Cognitive Processes in Composing (Flower \& Hayes, 1981) 
According to Flower and Hayes [16], cognitive process writing theory shows a major departure from the traditional paradigm of stages which are organized in a linear sequence or structure. In the Cognitive process theory of writing, each mental process has a hierarchical structure which may occur at any time in the composing process [16]. This theory suggests writing instructor should focus on students' mental acts, and it emphasizes the nonlinear sequence and hierarchical system of each composing process as presented in Figure 1. The authors believe that the working system of the Pigai program fits perfectly with the cognitive process theory of writing. Through the Pigai program, students can practice the cognitive writing model from the task environment component, reading through the writing prompts and identifying audience specification, where they construct knowledge structure on topic knowledge and audience based on their long-term memory. Then, they engage with the writing task in the online composing stage. After they submit the draft of their written products, students will receive instant automated feedback through the Pigai program, which leads to another round practice of process writing. Through the Pigai, students are constantly developing their mental capacity for writing. Moreover, the Pigai would raise their awareness of readers or audience when they provide feedback to their peers. In addition, they might be able to receive feedback from more intelligent peers which can lead the writer into the revision sub-process. Furthermore, the automated feedback of Pigai transforms the associated writing knowledge from short-term memory into students' long-term memory. Since the instant diagnostic and formative feedback in the forms of feedback on grammar, vocabulary, content, organization and mechanics leads to students' revising their written works constantly, their learning of writing skills will be enhanced by multiple recursive writing practices through the use of Pigai program. In this way, students' long-term capacity for writing knowledge would be enhanced.

\section{Framework for Using Pigai AWE in the EFL Writing Lesson}

By referring closely to the Cognitive process writing theory, as well as the core aspects of Cognitivism Constructivism and Socio-cultural theories, the authors suggest a framework for EFL writing instruction based on the integrated use of the Pigai AWE program along with teacher and peer feedback. The main procedures of the writing instruction are presented in Figure 2.

Step 1: The pre-writing stage: Students discuss the topic with their team members, brainstorming by drawing a mind map and taking notes, establishing a viewpoint and writing a rough draft, and editing their first draft.

Step 2: First draft - Students are required to finish their first draft in class.

Step 3: Experiencing the Pigai AWE program feedback - students use the Pigai program after class. They are asked to find the corresponding assignment via the Pigai website and post their first draft through the Pigai program.

Step 4: Draft 2 - After receiving automated feedback immediately, students are required to revise and edit their first draft into the second draft.

Step 5: Online peer feedback - After posting their second draft, they come to provide online peer feedback to their team members through the Pigai program.

Step 6: Draft 3 - Students are asked to revise their draft 2 , according to the received peer feedback, and submit their draft 3 via the Pigai program.

Step 7: Online teacher feedback - During the whole writing process, the teacher monitors the progress of each student. When the instructor notices those who finished the response to the peer feedback, the teacher will provide teacher feedback via the Pigai program.

Step 8: Draft 4 - Based on received teacher feedback, students are asked to revise their draft 3 , and edit it to draft 4 , which would be the final product, before they submit it to the teachers and for the Pigai for final grading.

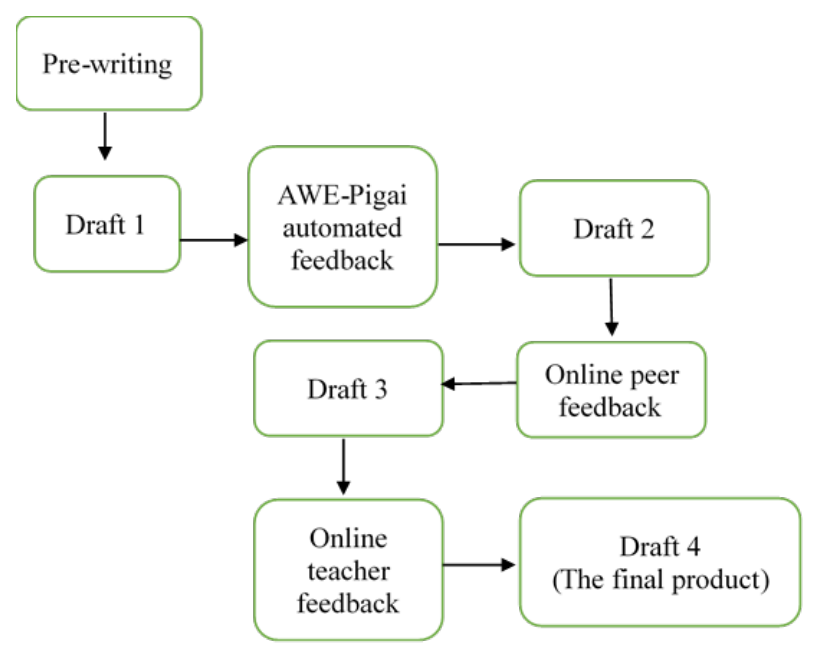

Figure 2. The main procedures of the integrated instruction of the Pigai AWE program

In this framework, the role of the instructor should not be a "knowledge feeder" [38], but a facilitator [20], where s/he provides constructive feedback to each draft when students engage in writing through the Pigai, and monitoring students' writing process. In addition, the instructor needs to afford cognitive instruction in the planning stage when students inquiry through the chat box of the Pigai to help their writing development.

Since the different qualities of online peer feedback may lead to different writing learning results, teacher supervision is necessary in order to enhance the reliability and validity of peer feedback [40]. Constant guidance and training are useful in helping students to provide a higher 
percentage of constructive feedback [8], such as adopting a peer feedback checklist. Furthermore, the instructor should explain the purpose of peer feedback explicitly and invite participants to start with positive feedback to build their confidence, where this can be an effective way to reduce the level of students' anxiety, which can break the barrier of cultural factors [26]. The key to the success of the implementation of the AWE program is found to be users' high frequency of its use [6]. Therefore, students need to finish the submission of their draft a certain number of times by the users is considered to be another strategy for this paradigm. The engagement of students writing through the Pigai program can be monitored by the teacher via the teacher's interface in the Pigai program.

\section{Conclusions}

To conclude, the authors reviewed 26 carefully selected research articles on the AWE program that were published in the past decade. Based on the systematic literature review, the authors found that there is little study on AWE program that was conducted especially in the aspect of experimental research and qualitative research. Future research are suggested to engage in more investigation in the nature of experimental research and qualitative research, in order to make the current findings more comprehensive, particularly in the Chinese context. That said, although the current research on the use of AWE is progressive and fruitful, the findings seem to be contradictory and insufficient in terms of causational empirical studies. Specifically, the Pigai program, being one of the most extensively implemented AWE programs in Chinese tertiary institutions, attracts many researchers' attention since its emergence in 2011. However, previous studies on Pigai's automated feedback mostly were conducted by a survey [47, 2, 44, 24], or an interview [24], in which these studies investigate the accuracy and users' perception, as well as its effectiveness on improving grammar skill through participant self-reported surveys and interviews. Therefore, there is a conspicuous gap to support the conclusions of the study of the Pigai program automated feedback, particularly to those studies on examining its effectiveness on improving writers' writing performance. In addition, the literature so far pays little attention to the constructive and sociocultural forces that influence the AWE automated feedback instruction. This article has discussed the theories, Cognitive Constructivism theory (particularly the use of Cognitive process writing theory) and Sociocultural Theory, which the authors believe are able to yield new findings for Chinese EFL teachers to make effective use of Pigai AWE program automated feedback in EFL writing class, and also to provide a framework for the instructor to bring in EFL writing teaching and learning in the Chinese context.

\section{Acknowledgements}

This research was made possible due to research grant in the scheme of Geran Putra (or Putra Grant) by Research Management Centre, Universiti Putra Malaysia (UPM).

\section{REFERENCES}

[1] Attali, Y., Lewis, W., \& Steier, M., "Scoring with the computer: Alternative procedures for improving the reliability of holistic essay scoring,” Language Testing, vol. 30, no. 1, pp. 125-141, 2013. Retrieved from URL: https://doi.org/10.1177/0265532212452396.

[2] Bai, L., \& Hu, G., "In the face of fallible AWE feedback: how do students respond?,” Educational Psychology, vol. 37, no. 1, pp. 67-81, 2017. Retrieved from URL:http://dx.doi.o rg/10.1080/01443410.2016.1223275.

[3] Britton, J. "The development of writing abilities," others, 1975, pp. 11-18.

[4] Bruner, J. "The Role of Dialogue in Language Acquisition.” In the Child's Conception of Language, ed. A. Sinclair, R. Jarvella, and W. Levelt. New York: Springer-Verlag, 1978.

[5] Chapelle, C. A., Cotos, E., \& Lee, J., "Validity arguments for diagnostic assessment using automated writing evaluation,” Language Testing, vol. 32, no. 3, pp. 385-405, 2015. Retrieved from URL: https://doi.org/10.1177/026553 2214565386

[6] Chen, C. F. E., \& Cheng, W. Y. E. C., "Beyond the design of automated writing evaluation: Pedagogical practices and perceived learning effectiveness in EFL writing classes," Language Learning \& Technology, vol. 12, no. 2, pp. 94-112, 2008.

[7] Chen, M., \& Xia, X. M., "The features and patterns of revision process in English learners' writing," Sino-US English Teaching, vol. 10, no. 1, pp. 58-64, 2013.

[8] Choi., J., "Online Peer Discourse in a Writing Classroom,” International Journal of Teaching and Learning in Higher Education, vol. 26, no. 2, pp. 217-231, 2014. Retrieved from URL: http://www.isetl.org/ijtlhe/

[9] Cotos, E. (2011). "Potential of Automated Writing Evaluation Feedback,” CALICO Journal, vol. 28, no, 2, pp. 420-459, 2011. DOI: 10.11139/cj.28.2.420-459.

[10] D'Angelo, F. J., A Conceptual Theory of Rhetoric, 1975.

[11] Dikli, S., \& Bleyle, S., “Automated Essay Scoring feedback for second language writers: How does it compare to instructor feedback?,” Assessing writing, vol. 22, pp. 1-17, 2014. Retrieved from URL: https://doi.org/10.1016/j.asw.2 014.03.006.

[12] Ding, T., “A study of an E-Comment generating system: Development \& application,” Unpublished master's thesis. National Tsinghua University of Education, Beijing, China, 2008

[13] Ene, E., \& Upton, T. A., "Synchronous and asynchronous teacher electronic feedback and learner uptake in ESL 
composition,” Journal of Second Language Writing, vol. 41, pp. 1-13, 2018. DOI: 10.1016/j.jslw.2018.05.005.

[14] Flower, L., "Writer-based prose: A cognitive basis for problems in writing," College English, vol.41, no. 1, 1979, pp. 19-37.

[15] Flower, L., \& Hayes, J. R., “The cognition of discovery: Defining a rhetorical problem,” College composition and communication, vol. 31, no. 1, pp. 21-32, 1980.

[16] Flower, L., \& Hayes, J. R., “A cognitive process theory of writing," College composition and communication, vol. 32, no. 4, pp. 365-387, 1981.

[17] Fosnot, C. T. "Enquiring teachers enquiring learners: A constructivist approach to teaching," New York: Teachers College Press, 1996.

[18] Gilles, C., \& Pierce, K. M. "Making room for talk: Examining the historical implications of talk in learning," English Education, 2003, pp. 36(1), 56-79.

[19] Graves, D. H., "Balance the basics: Let them write," Learning, vol. 6, no. 8, pp. 30-3, 1978.

[20] Hawkins, L. K., \& Razali, A. B., "A tale of 3 p's-penmanship, product, and process: 100 years of elementary writing instruction,” Language Arts, vol. 89, no. 5, pp. 305-317, 2012.

[21] Hoang, G. T. L., \& Kunnan, A. J., “Automated Essay Evaluation for English Language Learners: A Case Study of MY Access,” Language Assessment Quarterly, vol. 13, no. 4, pp. 359-376, 2016. DOI: 10.1080/15434303.2016.1230121

[22] Hyland, K., \& Hyland, F. (2006). "Contexts and issues in feedback on L2 writing," Feedback in second language writing: Contexts and issues, 2006, pp. 1-19.

[23] Jiang, Y. “An automated essay-evaluation corpus of English as a Foreign Language writing," British Journal of Educational Technology, vol. 46, no. 5, pp. 1109-1117, 2015.

[24] Lai, Y. H. "Which do students prefer to evaluate their essays: Peers or computer program,” British Journal of Educational Technology, vol. 41, no. 3, pp. 432-454, 2010

[25] Lee, I., "Revisiting teacher feedback in EFL writing from sociocultural perspectives,” Tesol Quarterly, vol. 48, no. 1, pp. 201-213, 2014.

[26] Li, L. Y., \& Vandermensbrugghe, J., "Supporting the thesis writing process of international research students through an ongoing writing group," Innovations in Education and Teaching International, vol. 48, no. 2, pp. 195-205, 2011.

[27] Li, Z., Link, S., Ma, H., Yang, H., \& Hegelheimer, V., “The role of automated writing evaluation holistic scores in the ESL classroom,” System, vol. 44, pp. 66-78. 2014. DOI: 10.1016/j.system.2014.02.007.

[28] Liao, H. C., "Using automated writing evaluation to reduce grammar errors in writing,” ELT Journal, vol. 70, no. 3, pp. 308-319, 2015. DOI: 10.1093/elt/ccv058.

[29] Liao, H. C., "Enhancing the grammatical accuracy of EFL writing by using an AWE-assisted process approach," System, vol. 62, pp. 77-92, 2016.

[30] Liu, S., \& Kunnan, A. J., "Investigating the Application of
Automated Writing Evaluation to Chinese Undergraduate English Majors: A Case Study of WriteToLearn,” CALICO Journal, vol. 33, no. 1, pp. 71-91, 2015. DOI: 10.1558/cj.v33i1.26380.

[31] Lu, Z., Li, X., \& Li, Z., “AWE-based corrective feedback on developing EFL learners' writing skill,” In Critical CALLProceedings of the 2015 EUROCALL Conference, Padova, Italy, 2015, pp. 375-380.

[32] Maybin, J., Mercer, N., \& Stierer, B. "Scaffolding learning in the classroom,” Thinking voices: The work of the national oracy project, 1992, pp. 186-195.

[33] Phillips, S. M., "Automated essay scoring: A literature review," Studies in Applied Linguistics and TESOL, vol. 11, no. 2, 2011. Retrieved from URL: https://doi.org/10.7916/s alt.v11i2.1396.

[34] Ramineni, C., "Validating automated essay scoring for online writing placement,” Assessing Writing, vol. 18, pp. 40-61, 2013.

[35] Reid, J. “The process of writing,” Englewood Cliffs, NJ: Prentice Hall, 1982

[36] Rudner, L. M., Garcia, V., \& Welch, C., "An evaluation of intelliMetric ${ }^{\mathrm{TM}}$ essay scoring system," The Journal of Technology, Learning and Assessment, vol. 4, no. 4, 2006. Retrieved from URL:http://ejournals.bc.edu/ojs/index.php/j tla/article/download/1651/1493.

[37] Stevenson, M., \& Phakiti, A., "The effects of computer-generated feedback on the quality of writing," Assessing Writing, vol. 19, pp. 51-65, 2014.

[38] Tai, H. C., Lin, W. C., \& Yang, S. C., "Exploring the effects of peer review and teachers' corrective feedback on EFL students' online writing performance,” Journal of Educational Computing Research, vol. 53, no. 2, pp. 284309, 2015

[39] Tang, J., \& Rich, C. S., “Automated writing evaluation in an EFL setting: Lessons from China,” JALT CALL Journal, vol. 13, no. 2, pp. 117-146. 2017.

[40] Topping, K. J., \& Ehly, S. W., "Peer assisted learning: A framework for consultation," Journal of Educational and Psychological Consultation, vol. 12, no. 2, pp. 113-132, 2011.

[41] Vygotsky, L. S. "Socio-cultural theory". Mind in society, 1978.

[42] Wang, M. J., \& Goodman, D., “Automated writing evaluation: students' perceptions and emotional involvement,” English Teaching \& Learning, vol. 36, no. 3, pp. 1 - 37, 2012.

[43] Wang, Y. “Artificial intelligence-based educational application: a survey of the significance for Chinese education,” International Journal of Smart Technology and Learning, vol. 1, no. 4, pp. 295-309, 2019.

[44] Wang, Y. J., Shang, H. F., \& Briody, P., "Exploring the impact of using automated writing evaluation in English as a foreign language university students' writing," Computer Assisted Language Learning, vol. 26, no. 3, pp. 234-257, 2013.

[45] Warschauer, M., \& Ware, P., “Automated writing evaluation: 
Defining the classroom research agenda," Language teaching research, vol. 10, no. 2, pp. 157-180, 2006. Retrieve from URL: http://dx.doi.org/10.1191/1362168806l r190oa.

[46] Woo, M. M., Chu, S. K. W., \& Li, X., "Peer-feedback and revision process in a wiki mediated collaborative writing," Educational technology research and development, vol. 61, no. 2, pp. 279-309, 2013.

[47] Yan, W. "Functions, Values \& Inadequacies------An Evaluative Discussion of Pigai Intelligent Online English Writing Correction System in View of Second Language
Acquisition,” Conference Series, 2019.

[48] Young, R. E., Becker, A. L., \& Pike, K. L., "Rhetoric: Discovery and change,” Harcourt College Pub, 1970. vol, 1.

[49] Zhang, Z. (V.), "Student engagement with computer-generated feedback: a case study,” ELT Journal, vol. 71, no. 3, pp. 317-328, 2016. Retrieve from URL: https://dx.doi.org/ 10.1093/elt/ccw089

[50] Zhang, Z., \& Zhang, Y., “Automated Writing Evaluation System: Tapping its Potential for Learner Engagement," IEEE Engineering Management Review, vol. 46, no. 3, pp. 29-33. 2018. DOI: 10.1109/emr.2018.2866150. 